\title{
Complete genome sequencing and phylogenetic analysis of dengue type 1 virus isolated from Jeddah, Saudi Arabia
}

Esam I Azhar ${ }^{1,2^{*}}$, Anwar M Hashem ${ }^{1,3}$, Sherif A El-Kafrawy ${ }^{1}$, Said Abol-Ela', Adly MM Abd-Alla ${ }^{1}$, Sayed Sartaj Sohrab ${ }^{1}$, Suha A Farraj ${ }^{1}$, Norah A Othman ${ }^{1}$, Huda G Ben-Helaby ${ }^{1}$, Ahmed Ashshi ${ }^{5}$, Tariq A Madani ${ }^{6}$ and Ghazi Jamjoom ${ }^{1}$

\begin{abstract}
Background: Dengue viruses (DENVs) are mosquito-borne viruses which can cause disease ranging from mild fever to severe dengue infection. These viruses are endemic in several tropical and subtropical regions. Multiple outbreaks of DENV serotypes 1, 2 and 3 (DENV-1, DENV-2 and DENV-3) have been reported from the western region in Saudi Arabia since 1994. Strains from at least two genotypes of DENV-1 (Asia and America/Africa genotypes) have been circulating in western Saudi Arabia until 2006. However, all previous studies reported from Saudi Arabia were based on partial sequencing data of the envelope (E) gene without any reports of full genome sequences for any DENV serotypes circulating in Saudi Arabia.
\end{abstract}

Findings: Here, we report the isolation and the first complete genome sequence of a DENV-1 strain (DENV-1-Jeddah1-2011) isolated from a patient from Jeddah, Saudi Arabia in 2011. Whole genome sequence alignment and phylogenetic analysis showed high similarity between DENV-1-Jeddah-1-2011 strain and D1/H/IMTSSA/98/606 isolate (Asian genotype) reported from Djibouti in 1998. Further analysis of the full envelope gene revealed a close relationship between DENV-1-Jeddah-1-2011 strain and isolates reported between 2004-2006 from Jeddah as well as recent isolates from Somalia, suggesting the widespread of the Asian genotype in this region.

Conclusions: These data suggest that strains belonging to the Asian genotype might have been introduced into Saudi Arabia long before 2004 most probably by African pilgrims and continued to circulate in western Saudi Arabia at least until 2011. Most importantly, these results indicate that pilgrims from dengue endemic regions can play an important role in the spread of new DENVs in Saudi Arabia and the rest of the world. Therefore, availability of complete genome sequences would serve as a reference for future epidemiological studies of DENV-1 viruses.

Keywords: Dengue virus, Full genome, Phylogenetic analysis, Diversity, Jeddah, Saudi Arabia

\section{Background}

Dengue virus (DENV) is a positive sense single-stranded RNA virus belonging to the Flaviviridae family. It is an endemic mosquito-borne virus affecting more than 50 million people globally [1]. Infection with any DENV serotype (DENV 1-4) can range from asymptomatic infection to mild dengue fever. On the other hand, reinfection with heterologous serotypes can lead to more

\footnotetext{
* Correspondence: eazhar@kau.edu.sa

${ }^{1}$ Special Infectious Agent Unit, King Fahd Medical Research Center, King Abdulaziz University, Jeddah, Kingdom of Saudi Arabia

${ }^{2}$ Department of Medical Laboratory Technology, Faculty of Applied Medical Sciences, King Abdulaziz University, Jeddah, Kingdom of Saudi Arabia Full list of author information is available at the end of the article
}

severe disease, i.e. dengue with warning signs or severe dengue infection $[2,3]$.

DENV genome varies in size from 10.6 to $11 \mathrm{~kb}$ and encodes three structural and seven non-structural proteins [4]. The structural proteins are comprised of the capsid (C), membrane (M) and envelope (E) proteins, and the non-structural proteins include the NS1, NS2A, NS2B, NS3, NS4A, NS4B and NS5. DENV genome is flanked by 94 nucleotides (nts) at $5^{\prime}$ untranslated regions (UTR) and 388-462 nts at the 3' UTR [5]. While the four DENV serotypes share 65-70\% sequence homology, they are further clustered into different genotypes due to the high mutation rates $[6,7]$.

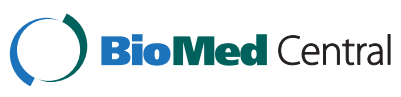

(c) 2015 Azhar et al.; licensee BioMed Central. This is an Open Access article distributed under the terms of the Creative Commons Attribution License (http://creativecommons.org/licenses/by/4.0), which permits unrestricted use, distribution, and reproduction in any medium, provided the original work is properly credited. The Creative Commons Public Domain Dedication waiver (http://creativecommons.org/publicdomain/zero/1.0/) applies to the data made available in this article, unless otherwise stated. 
Epidemiological and phylogenetic studies have shown geographical movement and divergence of DENVs [8-10]. Such studies have also shown an association between certain genotypes and disease severity. Shifts in circulating genotype or introduction of new genotypes or virulent strains in endemic regions have been shown to be linked with increased severity and occurrence of severe dengue infection $[11,12]$. Therefore, it is critically important to monitor circulating DENVs in endemic countries to better understand the epidemiology of the disease and to design and implement disease surveillance programs.

Millions of Muslims, from all over the world, visit Makkah and Al-Madinah every year to perform Hajj and Umrah. Jeddah city is the connection terminal where pilgrims gather on their way to the holy places in Makkah and Al-Madinah. Thus, pilgrims arriving from dengue endemic countries can play a major role in the introduction of new DENVs into Saudi Arabia. The large number of expatriates particularly from the Indian subcontinent, Southeast Asia and Africa, who work in Saudi Arabia and represent $\sim 20 \%$ of the population, as well as the leisure travel to dengue endemic countries in Southeast Asia, which is very common among Saudi citizens, represent other major sources of DENV importation into Saudi Arabia. All these factors could put Saudi Arabia at the crossroads for global spread of DENVs.

Several outbreaks have been reported in Saudi Arabia and neighboring country Yemen [13-20]. In 1994, DENV-1 and DENV-2 were reported to cause major outbreaks which were followed by the emergence of DENV-3 in 1997 [19]. Since then, all 3 serotypes (DENV 1-3) were being reported and isolated in Saudi Arabia [13-20]. Phylogenetic analysis indicate that recent isolates from both DENV-2 and DENV-3 belong to cosmopolitan genotype and genotype III, respectively, and there has been no major genetic changes since their first detection in Saudi Arabia [20]. On the other hand, most recent DENV-1 isolates belong to Asia genotype which might have replaced the pre-circulating America/Africa genotype that was first detected in 1994, although their co-circulation cannot be excluded [20]. Nonetheless, previous studies from Saudi Arabia have mainly focused on the analysis of small genomic sequences in the ENS1 junction or the E gene of DENVs for the determination of genetic variation and molecular characterization of isolated strains [20]. Furthermore, while several complete genome sequences of DENV-1 were reported for many strains around the world, no complete sequence for any DENV-1 isolated from Saudi Arabia has been reported yet. Here, we report the first complete genome and detailed genetic analysis of DENV-1 isolate obtained from a patient in Jeddah in Saudi Arabia in 2011 which should provide reference data for future genetic studies on DENV-1 in Saudi Arabia and the region.

\section{Results}

\section{Laboratory diagnosis}

A 26-year-old previously healthy Saudi women presented to the Emergency Department of King Abdulaziz University Hospital with primary dengue-like symptoms including fever, headache, myalgia, joint pain, nausea and vomiting. Laboratory investigations of the patient revealed a low platelet count of $63 \times 10^{3}$ cells $/ \mathrm{mm}^{3}$ $\left(150-450 \times 10^{3}\right.$ cells $\left./ \mathrm{mm}^{3}\right)$ and elevated liver enzymes levels; alanine amino transferase (ALT) $264 \mathrm{U} / \mathrm{L}$ (7-55 U/L), aspartate amino transferase (AST) $326 \mathrm{U} / \mathrm{L}(8-48 \mathrm{U} / \mathrm{L})$ and gamma glutaryl transferase (GGT) $240 \mathrm{U} / \mathrm{L}(9-48 \mathrm{U} / \mathrm{L})$. Further analysis showed that the patient's serum was positive for anti-dengue IgM but not anti-dengue IgG antibodies indicating an acute primary dengue infection. Real time RT-PCR confirmed these results and viral RNA was detected in the patient's plasma. Upon inoculation of plasma in C6/36 cells, cytopathic effect (CPE) was observed after 5 days (Figure 1) and the cell culture supernatant tested positive for DENV RNA by real time RT-PCR.

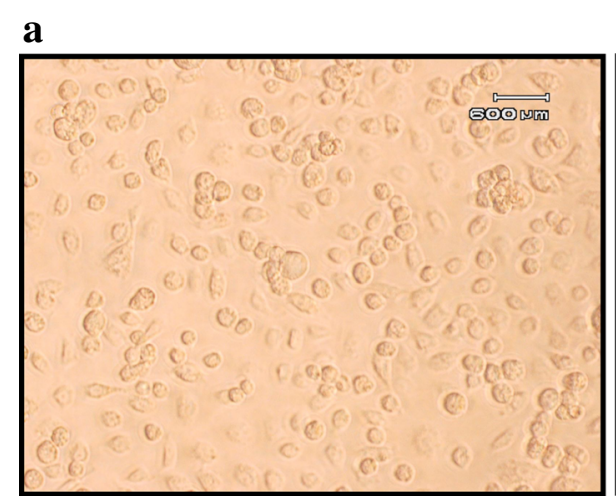

b

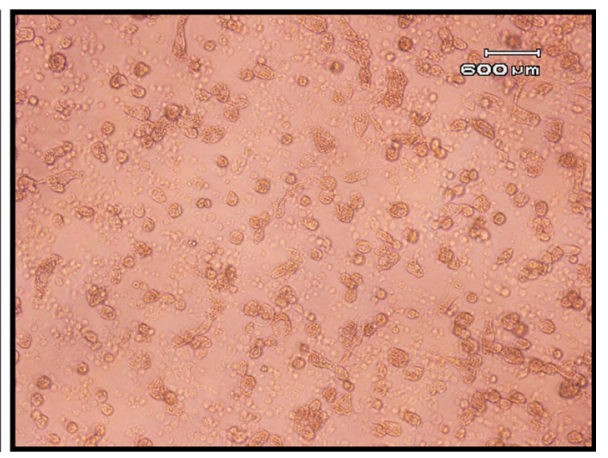

Figure 1 Dengue infected C6/36 cells. a. Uninfected C6/36 cells. b. CPE 5 days after inoculation of C6/36 cells with patient plasma. 
Complete genome sequence and phylogenetic analysis In order to characterize the DENV-1-Jeddah-1-2011 isolate, the full genome was sequenced. Assembly of all sequenced overlapping fragments obtained by RT-PCR resulted in a genome of 10,622 nts with a complete coding region encoding for 3392 amino acids (aa) flanked by 94 and 349 nts at the 5' UTR and 3' UTR, respectively. Identity matrix of nts and aa of DENV-1-Jeddah-1-2011 isolate was then compared to highly similar isolates (38 DENV-1 strains) available in GenBank. As shown in Table 1, sequence identity matrix of DENV-1-Jeddah-12011 isolate genome ranged from 97.2-89.6\% compared to other strains. On the other hand, aa identity was higher and ranged from 99.4-96.5\% (Table 1). Interestingly, the highest identity was with AF298808-Djibouti-1998 strain (97.2\% nt identity and $99.4 \%$ aa identity) followed by JN638336-Thailand-1986 strain (97.1\% nt identity and 99.2\% aa identity) and AB608788-Taiwan-1994 strain (96.7\% nt identity and $99 \%$ aa identity).

Comparison of the genome size of DENV-1-Jeddah-12011 isolate $(10,622 \mathrm{bp})$ with closely related isolates from other countries showed the AB608788-Taiwan1994 strain as the closest in genome size (10693 bp) followed by AF298808-Djibouti-1998 (10721 bp) and JN638336-Thailand-1986 (10735 bp) strains. Comparing the coding region of DENV-1-Jeddah-1-2011 isolate to the closest strain, AF298808-Djibouti-1998, 159 nt mutations were found with 27 non-synonymous substitutions only. Most of the aa changes were clustered in the NS5 region of the viral protein with only 1-3 substitutions in other genes (Table 2).

Although some recombination events might have occurred between some DENV-1 isolates (such as AB608788-Taiwan-1994 and AY726555-Myanmar-1998) as shown in Figure 2, recombination seems to be limited in these strains as only 9 out of 39 strains (23\%) showed high probability to have recombination events (Table 3). Importantly, DENV-1-Jeddah-1-2011 isolate did not show any recombination event with any of the tested strains.

To gain further understanding of genetic relationship between DENV-1-Jeddah-1-2011 isolate and other isolates, phylogenetic analysis of the whole viral genome was performed (Figure 3). As expected, DENV-1-Jeddah-12011 isolate clustered with AF298808-Djibouti-1998, JN638336-Thailand-1986 and AB608788-Taiwan-1994 strains in addition to AY726555-Myanmar-1998 and AF350498-China-2001 strains.

\section{Envelope protein gene}

Since DENV-1-Jeddah-1-2011 isolate genome represents the first reported complete genome of DENV-1 viruses from Saudi Arabia and that most available sequences in the GenBank are partial or complete coding sequences
Table 1 Nucleotide (NT) and amino acid (AA) identity of DENV-1-Jeddah-1-2011 full genome compared to closely related strains

\begin{tabular}{|c|c|c|}
\hline Strain & NT identity (\%) & AA identity (\%) \\
\hline AF298808-Djibouti-1998 & 97.2 & 99.4 \\
\hline JN638336-Thailand-1986 & 97.1 & 99.2 \\
\hline AB608788-Taiwan-1994 & 96.7 & 99.0 \\
\hline AF350498-China-2001 & 96.6 & 98.1 \\
\hline AY726555-Myanmar-1998 & 96.0 & 98.8 \\
\hline FJ469907-Singapore-2003 & 94.8 & 98.5 \\
\hline JN697058-Malaysia-2005 & 94.4 & 98.4 \\
\hline JN697057-Malaysia-2005 & 94.4 & 98.3 \\
\hline JN054255-SriLanka-2010 & 94.2 & 97.6 \\
\hline GQ398255-Singapore-2008 & 94.2 & 98.3 \\
\hline JN054256-SriLanka-2009 & 94.1 & 98.0 \\
\hline KF887994-Thailand-2013 & 94.1 & 98.0 \\
\hline AB074760-Japan-2001 & 93.9 & 97.5 \\
\hline KC759167-China-2012 & 93.8 & 97.7 \\
\hline JF459993-Myanmar-2002 & 93.5 & 98.2 \\
\hline KF955446-Vietnam-2008 & 92.9 & 96.5 \\
\hline AB074761-Japan-2001 & 91.5 & 97.6 \\
\hline AB189121-Indonesia-1998 & 91.2 & 97.3 \\
\hline AB189120-Indonesia-1998 & 91.2 & 97.5 \\
\hline KF184975-Angola-2013 & 91.1 & 97.0 \\
\hline FJ744701-Venezuela-2004 & 91.1 & 97.2 \\
\hline GQ868602-Phillipines-2004 & 91.1 & 97.4 \\
\hline $\begin{array}{l}\text { JQ915076-French Polynesia: } \\
\text { Tahiti-2009 }\end{array}$ & 90.8 & 97.3 \\
\hline $\begin{array}{l}\text { JQ915074-French Polynesia: } \\
\text { Moorea-2008 }\end{array}$ & 90.8 & 97.3 \\
\hline FJ850113-Nicaragua-2005 & 90.7 & 97.1 \\
\hline JX669475-Brazil-2002 & 90.6 & 97.0 \\
\hline JX669473-Brazil-2001 & 90.6 & 97.0 \\
\hline FJ810415-Venezuela-2005 & 90.6 & 97.1 \\
\hline JN903578-India-2007 & 90.6 & 97.0 \\
\hline FJ850114-Nicaragua-2005 & 90.4 & 97.0 \\
\hline KJ189368-Mexico-2012 & 90.2 & 96.9 \\
\hline JN903579-India-2008 & 90.2 & 96.8 \\
\hline KJ189369-Mexico-2011 & 90.0 & 97.1 \\
\hline KJ189366-Peurto Rico-2010 & 89.9 & 96.7 \\
\hline KJ189304-Colombia-2005 & 89.9 & 97.1 \\
\hline KJ189303-Colombia-1998 & 89.9 & 97.1 \\
\hline KJ189367-Peurto Rico-2010 & 89.8 & 96.9 \\
\hline KF921948-Vietnam-2008 & 89.6 & 97.6 \\
\hline
\end{tabular}

for the $\mathrm{E}$ protein only, we compared the $\mathrm{E}$ gene from DENV-1-Jeddah-1-2011 isolate to 57 selected DENV-1 isolates from various locations including isolates from 
Table 2 Amino acid substitutions observed in the DENV1-Jeddah-1-2011 isolate compared to AF298808-Djibouti1998 isolate

\begin{tabular}{|c|c|c|c|c|c|}
\hline \multirow[t]{2}{*}{ S.N } & \multirow[t]{2}{*}{ Gene } & \multicolumn{2}{|c|}{ Position } & \multicolumn{2}{|l|}{$A A$} \\
\hline & & $\overline{A A}$ & NT & $\begin{array}{l}\text { DENV-1- } \\
\text { Jeddah-1-2011 }\end{array}$ & $\begin{array}{l}\text { AF298808- } \\
\text { Djibouti-1998 } \\
\end{array}$ \\
\hline 1 & $\mathrm{CP}$ & 55 & 165 & $\mathrm{R}$ & $\mathrm{T}$ \\
\hline 2 & PreM & 178 & 534 & I & V \\
\hline 3 & $\mathrm{E}$ & 593 & 1779 & V & A \\
\hline 4 & & 618 & 1854 & L & S \\
\hline 5 & NS1 & 838 & 2514 & L & V \\
\hline 6 & & 855 & 2565 & $L$ & $\mathrm{~F}$ \\
\hline 7 & & 1129 & 3387 & S & L \\
\hline 8 & NS2A & 1187 & 3561 & V & I \\
\hline 9 & & 1275 & 3825 & A & $E$ \\
\hline 10 & NS2B & 1378 & 4134 & V & I \\
\hline 11 & NS3 & 1536 & 4608 & K & Q \\
\hline 12 & & 1543 & 4629 & $\mathrm{~T}$ & S \\
\hline 13 & & 2117 & 6351 & $\mathrm{~S}$ & $N$ \\
\hline 14 & NS4A & 2170 & 6510 & K & R \\
\hline 15 & & 2187 & 6561 & M & V \\
\hline 16 & NS5 & 2350 & 7050 & X & $L$ \\
\hline 17 & & 2364 & 7092 & $\mathrm{~T}$ & A \\
\hline 18 & & 2628 & 7884 & । & $\mathrm{T}$ \\
\hline 19 & & 2758 & 8274 & A & $\mathrm{T}$ \\
\hline 20 & & 2941 & 8823 & $\mathrm{~T}$ & $\mathrm{R}$ \\
\hline 21 & & 3013 & 9039 & D & G \\
\hline 22 & & 3035 & 9105 & $\mathrm{~T}$ & S \\
\hline 23 & & 3120 & 9360 & $L$ & I \\
\hline 24 & & 3133 & 9399 & E & Q \\
\hline 25 & & 3140 & 9420 & G & $\mathrm{E}$ \\
\hline 26 & & 3237 & 9711 & G & E \\
\hline 27 & & 3364 & 10092 & K & R \\
\hline
\end{tabular}

Saudi Arabia and many other Islamic countries as shown in Table 4. Comparison of nt sand aa sequences of DENV-1-Jeddah-1-2011 isolate showed high similarity to previously reported isolates from Jeddah collected between 2004-2006 (AM746212-Jeddah-2006, AM746213Jeddah-2006, AM746214-Jeddah-2005, AM746215-Jeddah2005, AM746216-Jeddah-2004 and AM746217-Jeddah2004). Interestingly, the E gene from two DENV-1 isolates from Somalia (KC848580-Somalia-2011 and KC848578Somalia-2011) in addition to AF298808-Djibouti-1998 showed high similarity to DENV-1-Jeddah-1-2011 isolate. The lowest similarity $(69.9 \% \mathrm{nt}$ and $76.5 \% \mathrm{aa})$ was found with DENV-1 isolate (JN036391-Bangladesh-2006) (Table 4). As expected, phylogenetic analysis of the complete E gene of DENV-1-Jeddah-1-2011 isolate with geographically diverse DENV-1 isolates and other DENV-1 Jeddah isolates showed DENV-1-Jeddah-12011 clustering with some of the DENV-1 strains previously identified and reported from Jeddah together with the African AF298808-Djibouti-1998 strain and very closely related to KC848580-Somalia-2011, KC848578Somalia-2011, AF350498-China-2011 and JN029818China-2010 (Figure 4).

\section{Discussion}

DENV-1 has been circulating in several cities in the western and southern regions of Saudi Arabia since 1994 [13,14,18-20]. Phylogenetic analysis of partial genome sequences from several DENV-1 isolates from Jeddah showed two distinct genotypes [20]. Early in 1994, DENV-1 isolates from Jeddah were from the America/Africa genotype. However, in 2004, circulating DENV-1 viruses were found to be from the Asian genotype in which they clustered with the African AF298808-Djibouti-1998 strain [20]. The later genotype continued to circulate in Saudi Arabia until 2006 [20]. In this study, we were interested to extend previous studies and to investigate the genetic relationship between circulating DENV-1 viruses in Saudi Arabia and other parts of the world, with emphasis on Islamic countries due to the religious ties between these countries and the holy places in Makkah and AlMadinah during Hajj pilgrimage and Umrah seasons. Jeddah, being the hub of transportation of Muslims coming in and out of the holy places in Makkah and Al-Madinah, is of particular interest since the large influx of pilgrims going through Jeddah could be a major source of virus transportation to the western region of the country.

Sequence alignment and phylogenetic analysis of the full-length genome of DENV-1-Jeddah-1-2011 isolate showed a very close relationship between this isolate and the African AF298808-Djibouti-1998 strain in the Asian genotype, suggesting that this genotype was circulating at least until 2011 in Saudi Arabia since its introduction. The observed genetic variation in DENV-1-Jeddah-12011 isolate compared to other related strains, both at the nt and aa levels, as well as the deletion in the 3'UTR are most likely due to local evolution and adaptation of this virus. Analysis of the deduced aa sequence of the DENV-1-Jeddah-1-2011 isolate compared to the most closely related strain (AF298808-Djibouti-1998), showed that most of the aa substitution were in the NS5 protein $(12 / 26)$ with only two changes in the E protein (Table 2), suggesting that using the $\mathrm{E}$ gene only for phylogenetic analysis might not be the best approach to study genetic relationship between DENVs.

Nonetheless, since most of the reported DENV sequences in the Genbank, including those from Saudi 


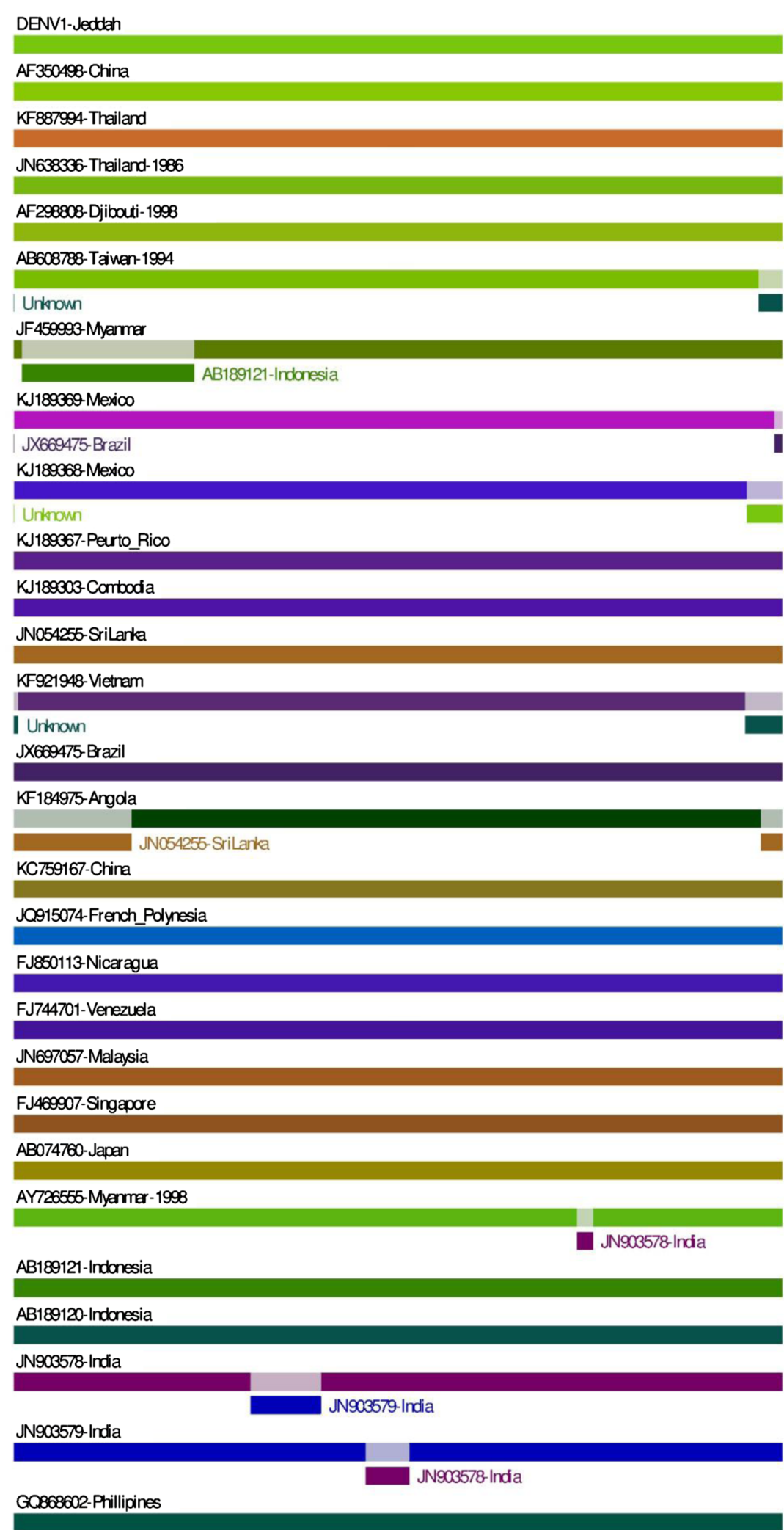

Figure 2 (See legend on next page.) 
(See figure on previous page.)

Figure 2 Recombination events in DENV-1 strains. Schematic representation indicates the recombination events in DENV-1 strains analyzed by RDP3 package with P-value $<0.05$. Continues lines indicate no recombination possibility. Analysis was performed on all sequences included in the phylogenetic tree in Figure 3. The following strains did not show any recombination events and are not shown in the figure; KJ189366-Peurto Rico-2010, KJ189304-Colombia-2005, JN054256-SriLanka-2009, KF955446-Vietnam-2008, JX669473-Brazil-2001, JQ915076-French Polynesia:Tahiti-2009, FJ850114-Nicaragua-2005, FJ810415-Venezuela-2005, JN697058-Malaysia-2005, GQ398255-Singapore-2008 and AB074761-Japan-2001.

Arabia, are from the $\mathrm{E}$ region, comparing the $\mathrm{E}$ gene from DENV-1-Jeddah-1-2011 to these sequences should give more insight into the genetic relatedness of these strains. Analysis of the E gene of DENV-1-Jeddah-12011 isolate compared to other reported sequences showed high similarity and close clustering of this strain with most recent isolates collected from Jeddah between 2004 and 2006 in addition to the African AF298808Djibouti-1998 strain (Figure 4). Interestingly, these viruses were closely related to two recent isolates from Somalia (KC848580-Somalia-2011 and KC848578-Somalia-2011) and China (AF350498-China-2011 and JN029818-China2010) (Table 4, and Figure 4). The high similarity between DENV-1-Jeddah-1-2011, the African AF298808-Djibouti1998 and the 2004-2006 isolates from Jeddah suggest that DENV-1 strains from the Asian genotype might have been imported with African pilgrims long before 2004. Additionally, the similarity of these strains to recent isolates from Somalia suggests the widespread of this genotype in this region most probably due to importation with Hajj pilgrims. Interestingly, the African AF298808-Djibouti1998 strain is more genetically related to Asian isolates than to African isolates [21] indicating that DENV strains can be transmitted and sustained in countries far from their geographic origin.

Detection of two DENV-1 genotypes in Saudi Arabia in the past two decades as well as the several outbreaks reported in Makkah, Al-Madinah and Jeddah [15,18-20] suggest that pilgrims could play a major role in the introduction and distribution of DENV serotypes in Saudi Arabia especially in the two holy cities of Makkah and Al-Madinah as well as Jeddah. While most recent
DENV-1 isolates from Jeddah belong to the Asian genotype, it is not known if this genotype completely replaced previously circulating America/Africa genotype or both genotypes are co-circulating due to the very limited number of published studies on DENVs from Saudi Arabia.

Introduction of new DENV viruses can lead to the emergence of recombinant strains which might have a great impact on the epidemiological and clinical outcomes. Interestingly, Tolou and colleagues reported that DENV-1 Singapore S275/90 strain is a product of a recombination event between viruses from two distinct lineages in which one lineage includes an African strain isolated in Abidjan in Ivory Coast and the other includes isolates from Djibouti (AF298808-Djibouti-1998) and the closely related isolate from Cambodia [21]. Identification of such events depends on the availability of full genome sequences of DENV strains from various regions which is missing in Saudi Arabia. Phylogenetic analysis of DENV-1-Jeddah-1-2011 isolate sequence, Asian genotype, did not show any genetic relations with the other DENV-1 genotypes including the America/Africa genotype which was circulating in Jeddah area since 1994. Furthermore, recombination analysis showed no such events in the DENV-1-Jeddah-1-2011 isolate.

\section{Conclusion}

In this study, we report the first complete genome sequence of DENV-1 isolate from Saudi Arabia which can represent a reference genome for future genetic studies of DENV-1 viruses. Sequence alignment and phylogenetic analysis of this isolate suggest that the Asian genotype might have been introduced into Saudi Arabia

Table 3 Recombination events positions

\begin{tabular}{|c|c|c|c|c|}
\hline \multirow[t]{2}{*}{ S.N. } & \multirow[t]{2}{*}{ Strain } & \multicolumn{2}{|c|}{ Break point position } & \multirow{2}{*}{$\begin{array}{l}\text { Av. P-Val with } \\
\text { RDP methods }\end{array}$} \\
\hline & & Beginning & Ending & \\
\hline 1 & AB608788-Taiwan-1994 & 10544 & 1 & $9.268 \times 10^{-34}$ \\
\hline 2 & JF459993-Myanmar-2002 & 99 & 2605 & $2.655 \times 10^{-66}$ \\
\hline 3 & KJ189369-Mexico-2011 & 10456 & 15 & $8.658 \times 10^{-05}$ \\
\hline 4 & KJ189368-Mexico-2012 & 10444 & 11 & $8.658 \times 10^{-05}$ \\
\hline 5 & KF921948-Vietnam-2008 & 10284 & 1 & $1.182 \times 10^{-99}$ \\
\hline 6 & KF184975-Angola-2013 & 10598 & 1667 & $1.705 \times 10^{-38}$ \\
\hline 7 & AY726555-Myanmar-1998 & 8023 & 8300 & $3.853 \times 10^{-06}$ \\
\hline 8 & JN903578-India-2007 & 3355 & 4395 & $3.881 \times 10^{-27}$ \\
\hline 9 & JN903579-India-2008 & 5014 & 5658 & $1.716 \times 10^{-03}$ \\
\hline
\end{tabular}




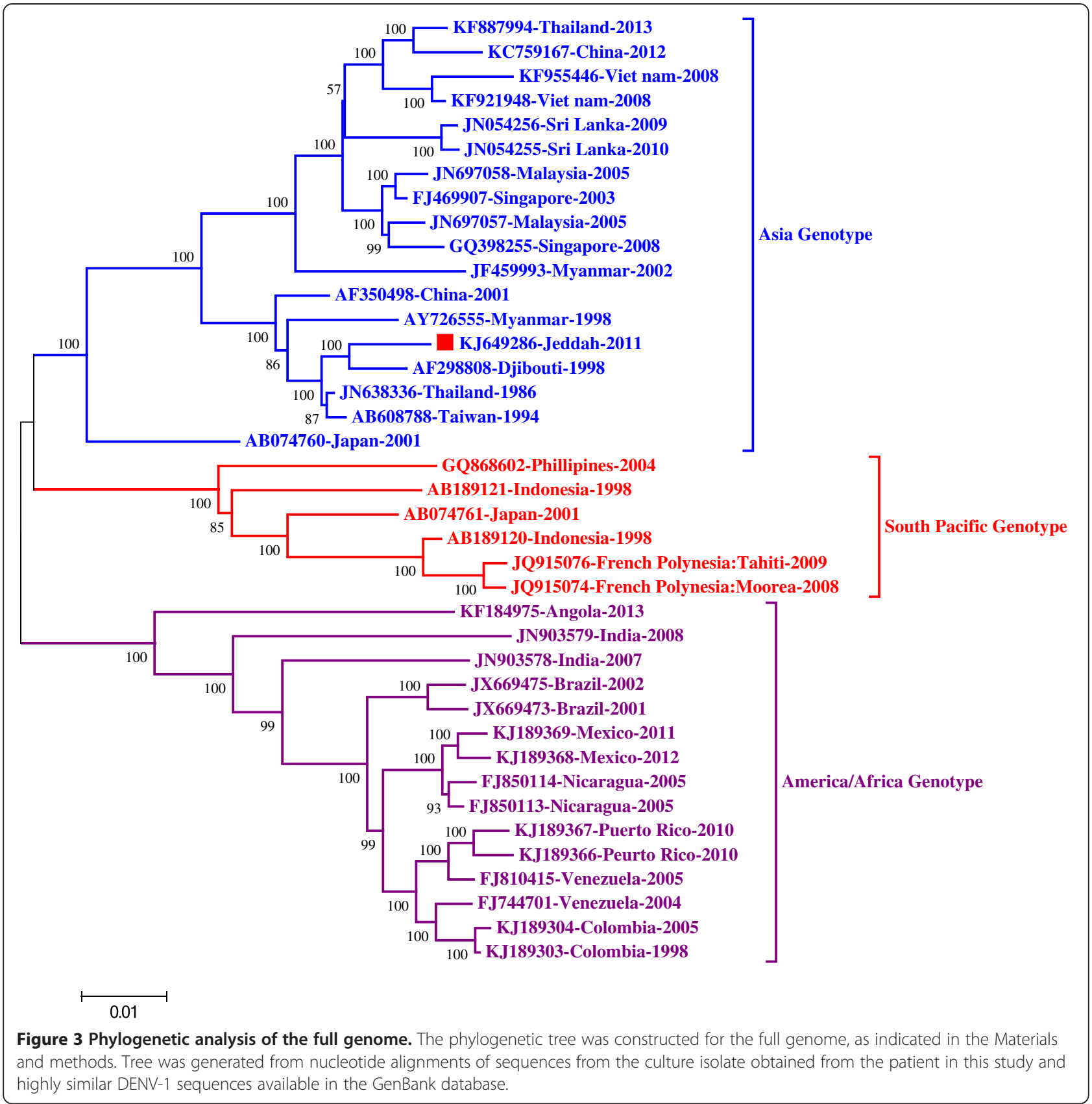

long before 2004 from the African continent probably through pilgrims. Pilgrims from all over the world, particularly dengue endemic regions, travel through Jeddah to Makkah and Al-Madinah in Saudi Arabia to perform Hajj and Umrah which can lead to the introduction and spread of new strains of DENV into Saudi Arabia as well as other geographical regions. While the high influx of pilgrims coming from DENV endemic areas to Jeddah and the holy places warrants further studies of more samples to have a clear picture about other circulating strains, availability of this complete genome sequence would serve as a reference for such future epidemiological, virological and genetic studies of DENV-1 viruses. Nonetheless, measures to screen pilgrims from DENV endemic areas might be critical to reduce the spread of the disease and the economic and healthcare burdens of the disease in Saudi Arabia and other parts of the world.

\section{Materials and methods}

\section{Samples}

Plasma and serum samples were collected from a female patient with suspected DENV infection at King Abdulaziz University Hospital and stored at $-80^{\circ} \mathrm{C}$ until testing. Ethical approval was obtained from the Biomedical Research 
Table 4 Nucleotide (NT) and amino acid (AA) identity of DENV-1-Jeddah-1-2011 E gene compared to closely related isolates

\begin{tabular}{|c|c|c|}
\hline Strain & NT identity (\%) & AA identity (\%) \\
\hline AM746214-Jeddah-SA-2005 & 99.7 & 99.8 \\
\hline AM746213-Jeddah-SA-2006 & 99.7 & 99.8 \\
\hline AM746216-Jeddah-SA-2004 & 99.5 & 99.6 \\
\hline AM746215-Jeddah-SA-2005 & 99.5 & 99.6 \\
\hline AM746212-Jeddah-SA-2006 & 99.4 & 99.6 \\
\hline AF298808-Djibouti-1998 & 98.7 & 99.5 \\
\hline AM746217-Jeddah-SA-2004 & 98.0 & 99.1 \\
\hline JN029818-China-2010 & 97.7 & 99.3 \\
\hline KC848580-Somalia-2011 & 97.5 & 99.1 \\
\hline AF350498-China-2001 & 97.1 & 98.5 \\
\hline KC848578-Somalia-2011 & 97.1 & 98.9 \\
\hline JN415511-Malaysia-2005 & 95.6 & 98.1 \\
\hline AB111077-Japan-2002 & 95.5 & 98.1 \\
\hline JN415496-Cambodia-2007 & 95.4 & 97.9 \\
\hline JN029807-China-2010 & 95.3 & 98.3 \\
\hline JQ993203-Thailand-2006 & 95.3 & 97.7 \\
\hline AB111076-Japan-2002 & 95.3 & 97.5 \\
\hline JQ403519-Taiwan-2009 & 95.2 & 97.9 \\
\hline KC861979-Vietnam-2002 & 95.2 & 98.1 \\
\hline JQ993204-Thailand-2007 & 95.2 & 98.1 \\
\hline JF967810-Myanmar-2008 & 95.1 & 97.5 \\
\hline JF967952-Cambodia-2010 & 95.0 & 97.9 \\
\hline JF967840-Myanmar-2008 & 94.9 & 97.7 \\
\hline JN415531-Australia-2008 & 94.8 & 97.7 \\
\hline JN415521-Singapore-2008 & 94.8 & 97.5 \\
\hline KC861978-Vietnam-2006 & 94.7 & 97.3 \\
\hline JQ403521-Taiwan-2010 & 94.7 & 98.1 \\
\hline KC589009-Indonesia-2012 & 94.6 & 97.9 \\
\hline JF967824-Singapore-2008 & 94.6 & 97.5 \\
\hline KC589010-Indonesia-2012 & 91.7 & 96.7 \\
\hline KF672791-Brazil-1991 & 91.5 & 97.1 \\
\hline KC812277-Peurto Rico-1998 & 91.3 & 96.9 \\
\hline AF425625-Nigeria-1968 & 91.3 & 96.3 \\
\hline KF672792-Brazil-1999 & 91.2 & 97.1 \\
\hline KC182085-Laos-2008 & 91.1 & 92.5 \\
\hline JN415486-India-2010 & 91.1 & 96.9 \\
\hline AM746220-Jeddah-SA-1994 & 91.1 & 96.7 \\
\hline AM746219-Jeddah-SA-1994 & 91.1 & 96.7 \\
\hline AM746218-Jeddah-SA-1994 & 91.1 & 96.7 \\
\hline EF654110-South Korea-2006 & 91.0 & 97.3 \\
\hline JN036371-Bangladesh-2009 & 91.0 & 96.7 \\
\hline JN415524-Sri Lanka-2004 & 90.9 & 96.9 \\
\hline
\end{tabular}

Table 4 Nucleotide (NT) and amino acid (AA) identity of DENV-1-Jeddah-1-2011 E gene compared to closely related isolates (Continued)

\begin{tabular}{lll}
\hline JN415516-Philippines2005 & 90.9 & 96.7 \\
JN415507-India-2008 & 90.9 & 96.5 \\
JX402212-Peurto Rico-2010 & 90.9 & 97.1 \\
JN415517-Philippines-2010 & 90.8 & 96.9 \\
JQ920432-Mexico-2010 & 90.7 & 96.7 \\
JN415513-Malaysia-2010 & 90.5 & 96.9 \\
JN415500-East Timor-2008 & 90.5 & 97.1 \\
JQ920431-Mexico-2010 & 90.5 & 96.7 \\
JF804024-French Polynesia-2001 & 90.5 & 92.5 \\
JN415532-Australia-2009 & 90.4 & 97.1 \\
JN415502-East Timor-2010 & 90.4 & 97.1 \\
JF800928-Nepal-2010 & 90.3 & 96.1 \\
EF654104-South Korea-2004 & 90.3 & 96.1 \\
KC182103-Laos-2008 & 86.4 & 88.0 \\
JN036391-Bangladesh-2006 & 69.9 & 76.5 \\
\hline
\end{tabular}

Ethical Committee at at King Abdulaziz University Hospital, King Abdulaziz University (reference \# 19-14).

\section{ELISA}

Serum sample was screened for anti-DENV IgM and IgG antibodies using Panbio Dengue IgM and IgG Capture ELISA Kits (Panbio, Australia) according to the manufacturer's instructions.

\section{RNA extraction and RT-PCR}

Viral RNA was extracted from plasma or culture supernatant using QIAamp viral RNA mini kit (Qiagen, Germany) according to manufacturer's instructions. Eluted RNA was screened for DENV-1 RNA by real time RT-PCR using primers and probes previously described [22].

\section{Virus isolation by cell culture}

Mosquito Aedes albopictus C6/36 cells maintained in complete Dulbecco's Modified Eagle's Medium (DMEM) supplemented with $2 \%$ fetal bovine serum (FCS), $2 \mathrm{mM}$ L-glutamine, $1.5 \mathrm{~g} / \mathrm{l}$ sodium bicarbonate, $1.0 \mathrm{mM}$ sodium pyruvate, $100 \mathrm{U} / \mathrm{ml}$ penicillin and $100 \mu \mathrm{g} / \mathrm{ml}$ streptomycin. Cells were incubated in a humidified atmosphere at $28^{\circ} \mathrm{C}$ in $5 \% \mathrm{CO}_{2}$. Cells were inoculated with $100 \mu \mathrm{L}$ of patient plasma and examined daily for CPE. After CPE is observed, cell culture supernatants were collected and analyzed by real time RT-PCR. DENV-1 RNA-positive culture supernatants were used for whole viral genome sequencing. 


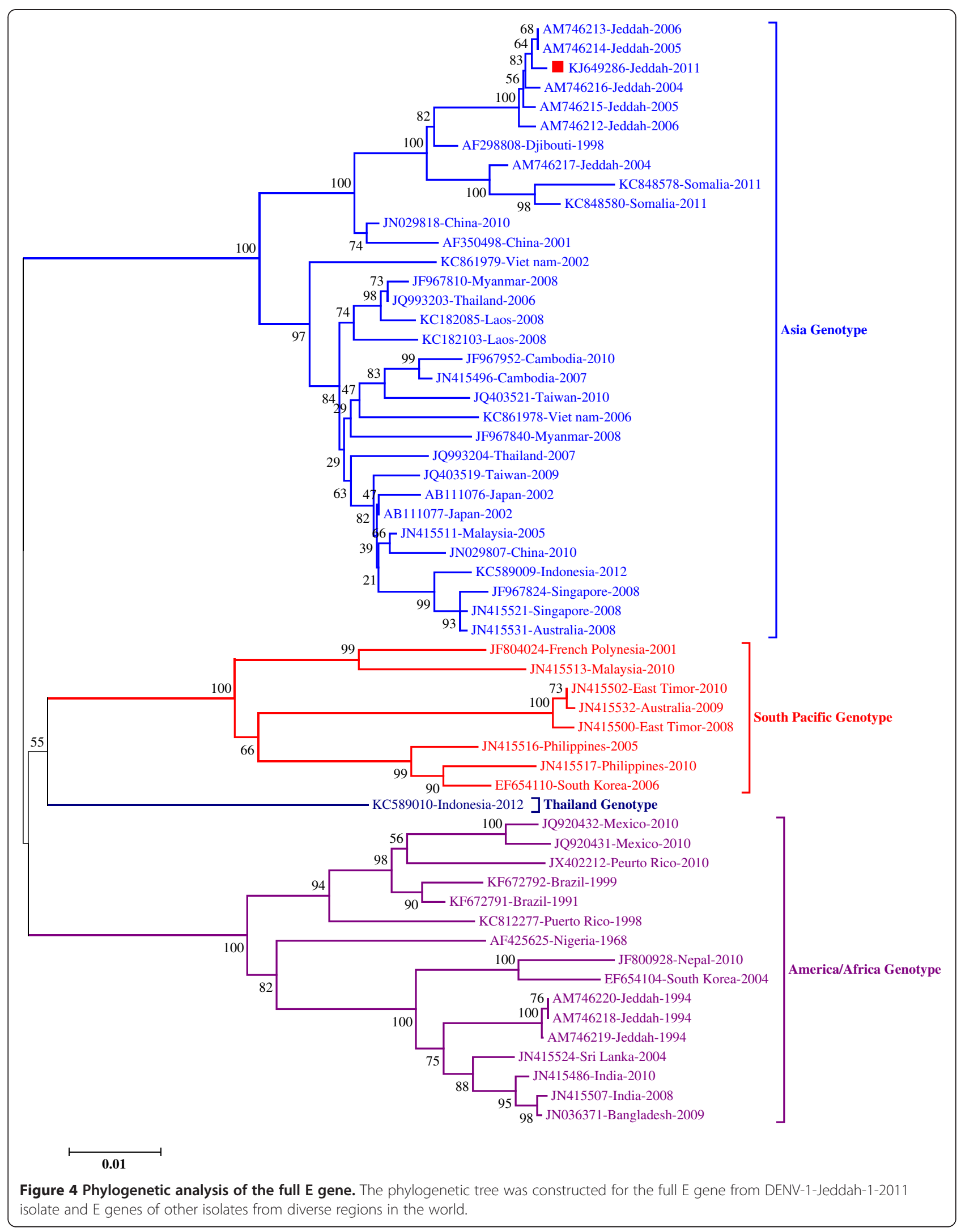




\section{DENV genome sequencing}

Viral RNA extracted from culture supernatant was subjected to RT-PCR amplification using primer pairs covering the whole length of the viral genome using an ABI Veriti thermal cycler (Applied Biosystems, USA) as previously described [23]. The RT-PCR amplified fragments (600-800 bp), which cover the whole genome sequence and overlap in common regions, were excised from agarose gel and purified using QIAquick Gel Extraction Kit (Qiagen, Germany) according to manufacturer's instructions. The products were subjected to cycle sequencing on an ABI 3500 Automatic Sequencer (Applied Biosystems, USA) using the Bigdye Terminator V3.1 Reaction Cycle Kit (ABI, Germany) according to manufacturer's instructions. The complete viral sequence was assembled and deposited in the GenBank with the following accession number (GenBank: KJ649286; DENV-1-Jeddah-1-2011).

\section{Sequence alignment, phylogenetic and recombination analysis}

The complete genome of DENV-1-Jeddah-1-2011 isolate was initially searched for similarity using BLAST software (http://www.ncbi.nlm.nih.gov/BLAST/). DENV-1 sequences with high similarity were selected for further analysis. Specifically, sequences were multiply aligned using ClustalW and nt sequences identity matrix as well as aa substitutions were analyzed. Phylogenetic analysis and distance calculations were performed using the MEGA v.5 software with the Neighbor-Joining method of the Maximum Composite Likelihood model, gamma-distributed rates among sites with 1,000 bootstrap replicates. Recombination analysis was conducted with RDP3 package with P-value $<0.05$ [24].

\section{Competing interests}

The authors declare no competing interests.

\section{Authors' contributions}

EIA, AA, SAE, AMMA, TAM and GJ conceived and designed the study, EIA and SAEK oversaw the laboratory work, SAF, NAO and HGBH performed the experiments, SSS and AMH analyzed the data, and SSS, SAEK and AMH wrote the manuscript. All authors read and approved the final manuscript.

\section{Acknowledgements}

This work was supported by grants funded from the Deanship of Scientific Research (DSR), King Abdulaziz University, Jeddah, Saudi Arabia, under Grant no. RG/34/2 and Grant no. 543/141/1432. The authors, therefore, acknowledge and thank DSR technical and financial support.

\section{Author details}

${ }^{1}$ Special Infectious Agent Unit, King Fahd Medical Research Center, King Abdulaziz University, Jeddah, Kingdom of Saudi Arabia. ${ }^{2}$ Department of Medical Laboratory Technology, Faculty of Applied Medical Sciences, King Abdulaziz University, Jeddah, Kingdom of Saudi Arabia. ${ }^{3}$ Department of Medical Microbiology and Parasitology, Faculty of Medicine, King Abdulaziz University, Jeddah, Kingdom of Saudi Arabia. ${ }^{4}$ Insect Pest Control Laboratory, Joint FAO/IAEA Program of Nuclear Techniques in Food and Agriculture, Vienna, Austria, Pests and Plant Protection Department, National Research Center, Cairo, Egypt. ${ }^{5}$ Department of Laboratory Medicine, Faculty of Applied
Medical Science, Umm Al-Qura University, Makkah, Kingdom of Saudi Arabia. ${ }^{6}$ Department of Medicine, Faculty of Medicine, King Abdulaziz University, Jeddah, Kingdom of Saudi Arabia.

Received: 30 September 2014 Accepted: 23 December 2014 Published online: 16 January 2015

\section{References}

1. San Martín JL, Brathwaite O, Zambrano B, Solórzano JO, Bouckenooghe A, Dayan $\mathrm{GH}$, et al. The epidemiology of dengue in the Americas over the last three decades: A worrisome reality. Am J Trop Med Hyg. 2010;82:128-35.

2. Anoop M, Issac A, Mathew T, Philip S, Kareem NA, Unnikrishnan R, et al. Genetic characterization of dengue virus serotypes causing concurrent infection in an outbreak in Ernakulam, Kerala, South India. Indian J ExpBiol. 2010:48:849-57.

3. Figueiredo RM, Naveca FG, Oliveira CM, BastosMde S, Mourão MP, VianaSde $S$, et al. Co-infection of Dengue virus by serotypes 3 and 4 in patients from Amazonas, Brazil. Rev Inst Med Trop Sao Paulo. 2011;53:321-3.

4. Green S, Rothman A. Immunopathological mechanisms in dengue and dengue hemorrhagic fever. CurrOpin Infect Dis. 2006;19:429-36.

5. Chambers TJ, Hahn CS, Galler R, Rice CM. Flavivirus genome organization, expression, and replication. Annu Rev Microbiol. 1990:44:649-488.

6. Anoop M, Mathew AJ, Jayakumar B, Issac A, Nair S, Abraham R, et al. Complete genome sequencing and evolutionary analysis of dengue virus serotype 1 isolates from an outbreak in Kerala, South India. Virus Genes. 2012;45:1-13.

7. Holmes EC, Twiddy SS. The origin, emergence and evolutionary genetics of dengue virus. Infect Genet Evol. 2003:3:19-28.

8. Kyle $J$, Harris E. Global spread and persistence of dengue. Annu Rev Microbiol. 2008:62:71-92.

9. Rico-Hesse R. Microevolution and virulence of dengue virus. Adv Virus Res. 2003;59:315-41.

10. Rico-Hesse R. Dengue virus virulence and transmission determinants. Curr Top Microbiol Immunol. 2010;338:45-55.

11. Rico-Hesse R, Harrison LM, Salas RA, Tovar D, Nisalak A, Ramos C, et al. Origins of dengue type 2 viruses associated with increased pathogenicity in the Americas. Virology. 1997;230:244-51.

12. Messer WB, Gubler DJ, Harris E, Sivananthan K, de Silva AM. Emergence and global spread of a dengue serotype 3, subtype III virus. Emerg Infect Dis. 2003;9:800-9.

13. Fakeeh M, Zaki AM. Dengue in Jeddah, Saudi Arabia, 1994-2002. Dengue Bull. 2003:27:13-8

14. Ahmed MM. Clinical profile of dengue fever infection in King Abdul Aziz University Hospital Saudi Arabia. J Infect Dev Ctries. 2010:4:503-10.

15. Khan NA, Azhar El, El-Fiky S, Madani HH, Abuljadial MA, Ashshi AM, et al. Clinical profile and outcome of hospitalized patients during first outbreak of dengue in Makkah, Saudi Arabia. Acta Trop. 2008;105:39-44.

16. Ayyub M, Khazindar AM, Lubbad EH, Barlas S, Alfi AY, Al-Ukayli S. Characteristics of dengue fever in a large public hospital, Jeddah, Saudi Arabia. J Ayub Med Coll Abbottabad. 2006;18:9-13.

17. Madani TA, Abuelzein e-TM, Al-Bar HM, Azhar El, Kao M, Alshoeb HO, et al. Outbreak of viral hemorrhagic fever caused by dengue virus type 3 in Al-Mukalla, Yemen. BMC Infect Dis. 2013:13:136.

18. El-Badry AA, El-Beshbishy HA, Al-Ali KH, Al-Hejin AM, El-Sayed WSM: Molecular and seroprevalence of imported dengue virus infection in Al-Madinah, Saudi Arabia. Comp Clin Pathol. 2013. doi.org/10.1007/s00580013-1704-x.

19. Fakeeh M, Zaki AM. Virologic and serologic surveillance for dengue fever in Jeddah, Saudi Arabia, 1994-1999. Am J Trop Med Hyg. 2001;65:764-7.

20. Zaki A, Perera D, Jahan SS, Cardosa MJ. Phylogeny of dengue viruses circulating in Jeddah, Saudi Arabia: 1994 to 2006. Trop Med Int Health. 2008;13:584-92

21. Tolou HJ, Couissinier-Paris P, Durand JP, Mercier V, de Pina JJ, de Micco P, et al. Evidence for recombination in natural populations of dengue virus type 1 based on the analysis of complete genome sequences. J Gen Virol. 2001:82:1283-90.

22. Drosten C, Göttig S, Schilling S, Asper M, Panning M, Schmitz H, et al. Rapid detection and quantification of RNA of Ebola and Marburg viruses, Lassa virus, Crimean-Congo hemorrhagic fever virus, Rift Valley fever virus, dengue virus, and yellow fever virus by real-time reverse transcription-PCR. J Clin Microbiol. 2002:40:2323-30 
23. Christenbury JG, Aw PP, Ong SH, Schreiber MJ, Chow A, Gubler DJ, et al. A method for full genome sequencing of all four serotypes of the dengue virus. J Virol Methods. 2010;169:202-6.

24. Martin DP, Lemey P, Lott M, Moulton V, Posada D, Lefeuvre P. RDP3: a

flexible and fast computer program for analyzing recombination.

Bioinformatics. 2010;26:2462-3.

Submit your next manuscript to BioMed Central and take full advantage of:

- Convenient online submission

- Thorough peer review

- No space constraints or color figure charges

- Immediate publication on acceptance

- Inclusion in PubMed, CAS, Scopus and Google Scholar

- Research which is freely available for redistribution 